\title{
Applying the 2005 Canadian Hypertension Education Program recommendations: 3 . Lifestyle modifications to prevent and treat hypertension
}

T ifestyle modification, al$\checkmark$ though often neglected, is an important strategy to prevent and treat hypertension and reduce antihypertensive drug burden. ${ }^{1,2} \mathrm{On}$ a population-wide basis, even a modest reduction in blood pressure of $3 \mathrm{~mm} \mathrm{Hg}$ may reduce the rate of death due to stroke by $8 \%$ and coronary artery disease by $5 \% .{ }^{1}$ Here we provide a summary of the expected reductions in blood pressure that may be achieved with various lifestyle interventions (Table 1).

\section{Rajdeep Padwal}

General Internal Medicine

University of Alberta

Edmonton, Alta.

Norman Campbell

Department of Medicine

University of Calgary

Calgary, Alta.

Rhian M. Touyz

Department of Nephrology

University of Ottawa

Ottawa, Ont.

For the Canadian Hypertension

Education Program

\begin{tabular}{|c|c|c|}
\hline \multirow[b]{2}{*}{ Intervention } & \multicolumn{2}{|c|}{$\begin{array}{l}\text { Mean blood pressure } \\
\text { reduction, } \mathrm{mm} \mathrm{Hg}(95 \% \mathrm{Cl})\end{array}$} \\
\hline & Systolic & Diastolic \\
\hline Weight loss (per kg lost) & $1.1(0.7-1.4)$ & $0.9(0.6-1.3)$ \\
\hline \multicolumn{3}{|l|}{ DASH diet } \\
\hline Hypertensive patients* & $11.4(7.0-16.0)$ & $5.5(2.7-8.2)$ \\
\hline Normotensive patients & $3.5(1.6-5.3)$ & $2.1(0.5-3.6)$ \\
\hline \multicolumn{3}{|c|}{$\begin{array}{l}\text { Sodium restriction (maximum } \\
78 \mathrm{mmol} \text { or } 1.8 \mathrm{~g} \text { daily) }\end{array}$} \\
\hline Hypertensive patients & $5.0(4.2-5.8)$ & $2.7(2.3-3.2)$ \\
\hline Normotensive patients & $2.0(1.5-2.6)$ & $1.0(0.6-1.4)$ \\
\hline \multicolumn{3}{|l|}{$\begin{array}{l}\text { Potassium supplementation } \\
\text { ( } 50 \mathrm{mmol} \text { or } 1.9 \text { g daily) }\end{array}$} \\
\hline Hypertensive patients & $4.4(2.2-6.6)$ & $2.5(0.1-4.9)$ \\
\hline Normotensive patients & $1.8(0.6-29)$ & $1.0(0.0-2.1)$ \\
\hline \multicolumn{3}{|c|}{$\begin{array}{l}\text { Aerobic exercise (120-150 min/wk } \\
\text { of walking, jogging or biking) }\end{array}$} \\
\hline Hypertensive patients & $4.9(2.7-7.2)$ & $3.7(1.8-5.7)$ \\
\hline Normotensive patients & $4.0(2.8-5.3)$ & $2.3(1.5-3.1)$ \\
\hline \multicolumn{3}{|c|}{$\begin{array}{l}\text { Alcohol restriction (from } 3-6 \\
\text { drinks to } 1-2 \text { drinks per day) }\end{array}$} \\
\hline Hypertensive patients & $3.9(2.7-5.0)$ & $2.4(1.6-3.3)$ \\
\hline Normotensive patients & $3.6(2.5-4.6)$ & $1.8(0.6-3.3)$ \\
\hline
\end{tabular}

*Hypertensive patients have a blood pressure of 140/90 or higher.
CASE: A 45-year-old man is being assessed for hypertension. His blood pressure readings are 165/95, 159/92, 152/90 and 149/90 over 4 successive visits to the office. Readings at home are similar, and he has no detectable target-organ damage. He has a body mass index (BMI) of $29 \mathrm{~kg} / \mathrm{m}^{2}$ and a waist circumference of $114 \mathrm{~cm}$. He does not exercise and drinks 3-4 glasses of vodka each night. He eats fast food frequently and liberally salts his meals. He asks you, his physician, to what degree lifestyle modifications might help to lower his blood pressure.

Question: How much weight loss is required to achieve a reduction in blood pressure?

Comment: Surprisingly little weight needs to be lost in order to reduce blood pressure. ${ }^{3}$ In a recent meta-analysis of 25 randomized controlled trials with a total of 4874 overweight or obese participants (mean BMI $\geq 0.7 \mathrm{~kg} / \mathrm{m}^{2}$ ), each kilogram of weight loss reduced systolic blood pressure by 1.1 (95\% CI $0.7-1.4) \mathrm{mm} \mathrm{Hg}$ and diastolic blood pressure by 0.9 (95\% CI $0.6-1.3) \mathrm{mm} \mathrm{Hg}$. The reduction in blood pressure was significantly greater in populations with an average weight loss of more than $5 \mathrm{~kg}$ than in those with less weight loss, for both systolic $(6.6$ [4.8-8.4] $\mathrm{mm} \mathrm{Hg} \mathrm{v}$. $2.7[0.8-4.6] \mathrm{mm} \mathrm{Hg})$ and diastolic (5.1 [3.8-6.6] mm Hg v.
$2.9[2.2-3.7] \mathrm{mm} \mathrm{Hg}$ ) blood pressure.

Question: How likely is it that this patient will be successful in lowering his body weight to a normal range?

Comment: Unfortunately, the vast majority of people who try to lose weight are unsuccessful, with most returning to their baseline weight within 5 years. ${ }^{3}$ Nevertheless, weight loss is still a worthy goal because it improves the global cardiovascular risk profile, lowers the risk of diabetes and enhances quality of life..$^{3,4}$ Although even brief counselling from a physician increases the likelihood that a patient will attempt weight loss by 3 -fold, less than $50 \%$ of eligible pa- 
tients receive such counselling.

It is, perhaps, unrealistic to expect that this patient will be able to reduce his body weight to normal. It should be emphasized to him that even a small weight reduction decreases blood pressure and may reduce or eliminate the need for antihypertensive therapy. A multimodal approach to weight loss, including dietary modification and exercise, is recommended. In people who are overweight or obese but not yet hypertensive, nonpharmacologic measures to reduce weight may prevent hypertension in the future.

Question: What is the optimal diet for blood pressure reduction? Comment: A diet similar to the Dietary Approaches to Stop Hypertension (DASH) diet should be recommended (Box 1, www .nhlbi.nih.gov/health/public/heart /hbp/dash). The DASH diet is rich in whole grains, fruits and vegetables and is consistent with Canada's Food Guide to Healthy Eating. It has been shown to be as successful as an antihypertensive drug in reducing blood pressure in people with hypertension. ${ }^{1}$

In addition to the DASH diet, lowering sodium intake to less than $100 \mathrm{mmol} / \mathrm{d}(2.4 \mathrm{~g}$ of sodium or $6 \mathrm{~g}$ of sodium chloride) is recommended, particularly for people who are likely to be saltsensitive (age over 45 years, Canadians of African descent, and people with impaired kidney function or diabetes mellitus). ${ }^{1}$

People with normal blood pressure who are at high risk of hypertension (e.g., if their blood pressure is in the high-normal range of 130-139/80-89 $\mathrm{mm} \mathrm{Hg}$ ) may achieve beneficial reductions in blood pressure by restricting their salt intake. Stricter regulation of sodium additives to food may be a helpful population measure to control hypertension. More information on the salt content of common foods can be found at www .health.gov/dietaryguidelines/dga 2005/document/html/chapter8 .htm. Patients eating sodiumrestricted diets should also be aware that, depending on their strength, water softeners may add up to $13 \mathrm{mmol}$ or $320 \mathrm{mg}$ of salt per litre of water intake to their diet.

Question: Is potassium supplementation required in this patient to lower his blood pressure?

Box 1: The Dietary Approaches to Stop Hypertension (DASH) eating plan*

Food group (examples or comments)

Recommended no.

Grains (whole wheat bread, oatmeal) of daily servings

Vegetables (tomatoes, potatoes, carrots,

$7-8$ beans, spinach, peas, squash)

Fruits (bananas, grapes, oranges, apricots, melons)

Low-fat dairy products (fat-free [skim] or low-fat [1\%] milk, yogurt, cheese)

Meats (primarily poultry or fish; select lean meats and prepare by trimming fat and broiling, roasting or boiling. Remove skin from poultry)

Nuts, seeds, dry beans (peanuts, walnuts, almonds, sunflower seeds, lentils)

Fats and oils (soft margarines, vegetable oil [e.g., olive, corn, canola or safflower])

Sweets (maple syrup, sugar, jam, jelly, hard candy, sorbet)

4-5

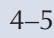

$2-3$

$\leq 2$

4-5/week

$2-3$

$5 \times /$ week

*The DASH Eating Plan is available at www.nhlbi.nih.gov/health/public/heart/hbp/dash /index.htm.
Comment: The mechanism by which potassium lowers blood pressure is unclear. On average, a mean increase in potassium intake of $50 \mathrm{mmol}$ or $1.9 \mathrm{~g}$ per day lowers systolic blood pressure by 4.4 (95\% CI 2.2-6.6) $\mathrm{mm} \mathrm{Hg}$ and diastolic blood pressure by 2.5 (95\% CI 0.1-4.9) $\mathrm{mm} \mathrm{Hg}$ in hypertensive patients and by 1.8 (95\% CI 0.6-2.9) over 1.0 (95\% CI $0.0-2.1) \mathrm{mm} \mathrm{Hg}$ in patients with normal blood pressure. This reduction must be balanced against the cost of supplementation and the risk of hyperkalemia, particularly in elderly people with unrecognized renal insufficiency or in patients taking potassium-sparing diuretics or renin-angiotensin inhibitors. Since a DASH-type diet is already rich in potassium, the Canadian Hypertension Education Program does not recommend routine additional supplementation beyond this diet.

Question: How much and what type of exercise will you recommend for this patient?

Comment: We recommend that physicians prescribe 30-60 minutes of moderate-intensity aerobic exercise daily for 4-7 days per week (see Table 1 for the effects on blood pressure). ${ }^{2}$ More information on Canada's Physical Activity Guide to Healthy Active Living and recommendations for exercise can be found at www.phac-aspc.gc .ca/pau-uap/paguide. Currently, resistance training (weightlifting) cannot currently be routinely recommended for patients with hypertension because of the theoretical risks associated with large exercise-induced surges in blood pressure, particularly if improper techniques are employed.

Question: What recommendations should be made regarding this patient's alcohol intake?

Comment: Increased alcohol consumption is often unrecognized as a cause of blood pressure elevation. Reducing alcohol intake lowers blood pressure (Table 1), with greater reductions being observed in 
people with higher baseline blood pressure. ${ }^{1}$

It is recommended that healthy adults limit their weekly alcohol consumption to fewer than 14 standard drinks for men and 9 standard drinks for women. ${ }^{1} \mathrm{~A}$ standard drink is about $43 \mathrm{~mL}$ or $1.5 \mathrm{oz}$ of spirits $(40 \%$ alcohol), $341 \mathrm{~mL}$ or $12 \mathrm{oz}$ of beer ( $5 \%$ alcohol) or $142 \mathrm{~mL}$ or 5 oz of wine (12\% alcohol). Simple advice and brief counselling to recommend the reduction on alcohol intake increases the likelihood that the patient will drink less.

\section{Conclusion}

Overall, lifestyle modification counselling should be offered to all patients with or at risk of hypertension. ${ }^{1,2}$ The main challenge remains the optimal implementation of such lifestyle strategies. Apart from advice from health care professionals, government legislation and regulation as well as societal change will be necessary to aid patients in choosing and sustaining healthy lifestyle decisions.
This article has been peer reviewed.

Competing interests: None declared for Rajdeep Padwal. Norman Campbell has given talks sponsored by numerous pharmaceutical companies and sits on the medical advisory boards of numerous companies. He has received research funding from Pfizer Canada and Sanofi-Aventis-Bristol Myers Squibb and has received funds to travel to meetings from Servier Canada, Roche and Pfizer Canada. Rhian Touyz has received educational grants and honoraria from Pfizer Canada, Fujisawa Pharmaceutical, Merck and Bristol Myers Squibb.

\section{References}

1. Touyz RM, Campbell N, Logan A, Gledhill N, Petrella R, Padwal R, et al. The 2004 Canadian recommendations for the management of hypertension: Part III - Lifestyle modifications to prevent and control hypertension. Can 7 Cardiol 2004;20:55-9.

2. Khan NA, McAlister FA, Lewanczuk R, Touyz RM, Padwal R, Rabkin SW, et al. The 2005 Canadian Hypertension Education Program recommendations for the management of hypertension: Part II - Therapy. Can 7 Cardiol 2005;21:657-72.

3. National Heart, Lung, and Blood Institute Obesity Education Initiative. Clinical guidelines on the identification, evaluation, and treatment of overweight and obesity in adults: the evidence report. Bethesda, MD: U.S. Department of Health and Human Services, Public Health Service, National Institutes of Health, National Heart, Lung, and Blood Institute; 1998.

4. Diabetes Prevention Program Research Group. Reduction in the incidence of type 2 diabetes with lifestyle intervention or metformin. $N$ Engl $\mathcal{F}$ Med 2002;346:393-403.

\section{Articles to date in this series}

McAlister FA, Wooltorton E, Campbell NRC. The Canadian Hypertension Education Program (CHEP) recommendations: launching a new series. CMAJ 2005;173(5):508-9.

Bolli P, Myers M, McKay D. Applying the 2005 Canadian Hypertension Education Program recommendations: 1. Diagnosis of hypertension. CMAJ 2005;173(5):480-3.

Hemmelgarn BR, Grover S, Feldman RD. Applying the 2005 Canadian Hypertension Education Program recommendations: 2. Assessing and reducing global atherosclerotic risk among hypertensive patients. CMAJ 2005;173(6):593-5.

\section{BOOKS ReCEIVED}

Baranek PM, Deber RB, Williams AP. Almost home: reforming home and community care in Ontario. Toronto: University of Toronto Press; 2004. 340 pp. $\$ 29.95$ ISBN 0-8020-8639-X

Bordowitz G. The AIDS crisis is ridiculous and other writings, 1986-2003. Cambridge (MA): MIT Press; 2004. 307 pp. US\$35.00 ISBN 0-262-02570-1

Cush J, Kavanaugh A, Stein M. Rheumatology: diagnosis and therapeutics. Baltimore: Lippincott Williams and Wilkins; 2004. 573 pp. \$51.95 ISBN 0-78175732-0

Eng P, Cheah F-K. Interpreting chest $\mathrm{X}$-rays: illustrated with 100 cases. New York: Cambridge University Press; 2005. 202 pp. \$45.00 ISBN 0-521-60732-9

Grant T, Carter S. Women in medicine: A celebration of their work. Richmond Hill: (ON): Firefly; 2004. 191 pp. \$39.95 ISBN 1-55297-906-7

Janigan DT. Environmental illness: Nova Scotia, 1983-2003. Black Point, NS: Fernwood Publishing; 2004. 128 pp. \$15.95 ISBN 1-55266-152-0

Jemieux-Charles L, Champagne F. Using knowledge and evidence in health care. Toronto: University of Toronto Press; 2004. 290 pp. \$60.00 ISBN 0-8020-8932-1
Montague, T. Patients first: closing the health care gap in Canada. Hoboken (NJ): John Wiley \& Sons; 2004. 192 pp. \$49.99 ISBN 0-470-83511-7

Roy R. Chronic pain, loss and suffering. Toronto: University of Toronto Press; 2004. 225 pp. \$60.00 ISBN 0-8020-3597-3

Weir M. Hypertension. Philadelphia: American College of Physicians; 2005. 259 pp. $\$ 42.00$ ISBN 1-930513-58-5 